\title{
TRANSFORMAÇÕES NA ESTRUTURA PRODUTIVA DA ECONOMIA PARANAENSE NOS ANOS 80 E $90^{*}$
}

\author{
Rossana Lott Rodrigues ${ }^{\S}$ \\ José Luiz Parré \\ Antonio Carlos Moretto ${ }^{\dagger}$ \\ Alexandre Florindo Alves
}

\begin{abstract}
RESUMO
Este artigo apresenta a evolução da estrutura produtiva da economia paranaense nas décadas de 1980 e 1990. Para tanto, estimou-se uma série de 5 matrizes de insumo-produto para os anos de 1980, 1985, 1990, 1995 e 1999, divididas em 32 setores, a partir das quais foram calculados o campo de influência, os índices de ligação de Hirschman-Rasmussen e puros e os multiplicadores setoriais. Esses indicadores permitiram identificar, além dos setores-chave, a evolução das relações econômicas e interindustriais no período. Os resultados mostraram tendência de diversificação da estrutura produtiva estadual e de maior abertura comercial, refletida nos menores índices de ligações internas e nos multiplicadores de produção.
\end{abstract}

Palavras-chave: insumo-produto, mudanças estruturais, relações intersetoriais, economia regional, Paraná.

\begin{abstract}
This article presents the evolution of the productive structure of the economy of the State of Paraná in the 1980's and 1990's. A set of 5 regional input-output matrices, divided in 32 sectors, was estimated for the years of 1980, 1985, 1990, 1995 and 1999, in order to calculate the field of influence, the Hirschman-Rasmussen and pure linkages and the sectors multipliers. These indicators allowed to identify, besides the key sectors, the evolution of economic and inter-industrial relationships in the period. The results showed trends of diversification in the productive structure of State and of greater commercial opening, both reflected in fewer internal linkages and in production multipliers.
\end{abstract}

Keys-words: input-output, structural changes, intersectoral relationships, regional economics, Paraná.

JEL classification: C67, O18.

\footnotetext{
* Os autores agradecem os comentários e sugestões de dois pareceristas anônimos.

$\S$ Professora Doutora do Departamento de Economia da Universidade Estadual de Londrina, Paraná. E-mail: rlott@uel.br.

a. Professor Doutor do Departamento de Economia da Universidade Estadual de Maringá, Paraná. E-mail: jlparre@uem.br.

$\dagger$ Professor Doutor do Departamento de Economia da Universidade Estadual de Londrina, Paraná. E-mail: acmoretto@uel.br.

† Professor Doutor do Departamento de Economia da Universidade Estadual de Maringá; Paraná. E-mail: afalves@uem.br. Endereço para contato: Universidade Estadual de Londrina - Campus Universitário - Centro de Estudos Sociasi Aplicados - Departamento de Economia - Rodovia Celso Garcia Cid, Km 380 - CEP: 86051-990 - Londrina - Paraná.

Recebido em junho de 2005. Aprovado em fevereiro de 2007.
} 


\section{INTRODUÇÃO}

Vários são os estudos que destacam a evolução da economia paranaense, isoladamente ou em relação à brasileira no final do século XX, todos eles buscando evidenciar as mudanças ocorridas na estrutura produtiva estadual num contexto de rápidas e grandes transformações da economia nacional inserida num contexto crescentemente globalizado.

É sabido que a década de 1980 foi um período de declínio da tendência de rápido crescimento e diversificação do aparelho produtivo estadual iniciado na década anterior. Mesmo assim, a economia paranaense apresentou taxa de crescimento bem superior à registrada para o país. No período 1980-1989, o PIB estadual cresceu 5,7\% ao ano enquanto a média nacional foi de 2,8\% (Lourenço, 1994).

De acordo com Trintin (2001), no período 1985-1998 cresceu a participação, no valor adicionado, do conjunto dos setores da metal-mecânica, sendo que perdem participação setores tradicionais, como produtos alimentares, madeira e têxtil.

Segundo Vasconcelos e Castro (1999), o Estado do Paraná tem despertado interesse em âmbito nacional, por ter sido palco privilegiado das transformações em curso na economia brasileira: a construção de um perfil produtivo com presença maior de setores de bens de consumo durável e de capital; a reestruturação do complexo agroalimentar - em ritmo muito influenciado pelo Mercado Comum do Sul (Mercosul) -, e uma intensa redistribuição patrimonial envolvendo fusões, aquisições e privatização de serviços de infra-estrutura.

Em função desses aspectos locacionais e de infra-estrutura, a economia paranaense pôde se tornar receptora de investimentos, o que provocou mudanças importantes na composição interna dos gêneros da indústria na década de 1990, com tendência de ganho de importância por parte dos setores produtores de bens mais elaborados como, por exemplo, o fato de o setor de abate de animais e preparação de conservas ter alcançado o segmento de beneficiamento de cereais, café e afins (Trintin, 2001).

Neste cenário, é importante ressaltar que as condições internas favoráveis à atração de novas indústrias começaram a se estabelecer desde meados da década de 1970, quando ocorreram mudanças no processo de industrialização com a emergência do complexo metal-mecânico centrado espacialmente em Curitiba, capital do Estado.

Contudo, foi a implantação de novas indústrias em razão do movimento de localização das empresas automobilísticas na RMC (Região Metropolitana de Curitiba), sustentadas por incentivos governamentais, a partir de meados dos anos 90, que trouxe dinamismo ao discreto crescimento industrial vivido na década de 1980, devido aos graves problemas econômicos pelos quais passou o país e que afugentaram os capitais internacionais, como salientado anteriormente.

Assim, a ação do governo estadual foi decisiva para atrair os novos investimentos, demonstrando o interesse do Estado na implementação de seu projeto de industrialização, por intermédio da concessão de incentivos de toda ordem às indústrias, em particular às montadoras de automóveis, para que se instalassem no Paraná. Em razão da implantação da Renault e da Audi-Volkswagen e do seu funcionamento em rede que desencadeou uma série de investimentos de seus fornecedores diretos, o Paraná inseriu-se no contexto da indústria automobilística nacional.

Além da diversificação na estrutura produtiva, outro destaque é a evolução dos vínculos mais fortes e qualitativamente diferenciados da economia paranaense com os mercados nacional e internacional a partir de 1985, processo marcado pela presença de novos segmentos industriais, segundo Trintin (2001). 
A Tabela 1 mostra os dados de distribuição das vendas da indústria do Paraná, por mercado de destino, e a distribuição das compras, por mercado de origem, de 1985 a 1998, evidenciando maior grau de inserção da economia paranaense em outros Estados e no exterior.

No caso do destino dos produtos, tanto dos segmentos que se implantaram durante o ciclo expansivo quanto daqueles tradicionais, o destaque é para outros Estados. Por outro lado, no que se refere à origem, sobressaem o exterior e outros Estados, nessa ordem, evidenciando estrangulamentos internos quanto à capacidade de fornecimento de insumos mais elaborados para atender à demanda dos setores mais modernos.

Dentro desse contexto, o objetivo geral desse artigo foi analisar a evolução da estrutura produtiva paranaense nos anos de 1980, 1985, 1990, 1995 e 1999, especificamente no que se refere às alterações relativas às ligações setoriais, usando o instrumental de insumo-produto.

Tabela 1 - Distribuição das vendas da indústria do Paraná, por mercado de destino, e distribuição das compras, por mercado de origem, 1985 e 1998

\begin{tabular}{lcc}
\hline Destino & 1985 & 1998 \\
\hline Para o Estado & 52,15 & 47,37 \\
Para outros Estados & 37,12 & 43,61 \\
Para o exterior & 10,72 & 9,03 \\
Origem & & \\
Do Estado & 60,81 & 53,17 \\
De outros Estados & 34,65 & 36,27 \\
Do exterior & 4,54 & 10,55 \\
\hline
\end{tabular}

Fonte: Trintin (2001).

Para Schaffer (1999), a representação das transações na forma de matriz, além de economia na apresentação (em relação ao sistema de partidas dobradas), permite ganho de percepção da interação que existe entre os setores.

Além desta Introdução, o artigo se estrutura em mais três partes. A primeira descreve os procedimentos metodológicos, enquanto a segunda apresenta os resultados e as discussões. Por fim, na terceira são tecidas algumas considerações finais.

\section{Procedimentos metodológicos}

As informações para a realização do estudo estão contidas nas matrizes de insumo-produto estimadas por Moretto (2000), Rodrigues (2000) e Parré e Alves (2002) para o Paraná, para os anos em tela, agregadas em 32 setores (Quadro 1). 


\section{Quadro 1 - Agregação dos setores das matrizes de insumo-produto do Brasil usada nas matrizes estimadas para o Paraná}

\begin{tabular}{|c|c|c|c|}
\hline Ordem & SETORES DA MATRIZ DO BRASIL-IBGE & Ordem & SETORES DAS MATRIZES ESTIMADAS PARA O PARANÁ \\
\hline 1 & Agropecuária & 1 & Agropecuária \\
\hline 2 & Extrativa Mineral & 2 & Extrativa Mineral \\
\hline 3 & Extração de Petróleo e Gás & & \\
\hline 4 & Minerais Não-Metálicos & 3 & Fabricação de Minerais Não-Metálicos \\
\hline 5 & Siderurgia & 4 & Metalurgia \\
\hline 6 & Metalurgia Não-Ferrosos & & \\
\hline 7 & Outros Metalúrgicos & & \\
\hline 8 & Máquinas Tratores & 5 & Máquinas e Equipamentos \\
\hline 9 & Material Elétrico & 6 & Material Elétrico/Eletrônico \\
\hline 10 & Equipamentos Eletrônicos & & \\
\hline 11 & Automóveis, Caminhões e Ônibus & 7 & Material de Transporte \\
\hline 12 & Outros Veículos e Peças & & \\
\hline 13 & Madeira e Mobiliário & 8 & Madeira e Mobiliário \\
\hline 14 & Papel e Gráfica & 9 & Celulose, Papel e Gráfica \\
\hline 15 & Indústria da Borracha & 10 & Indústria da Borracha \\
\hline 16 & Elementos Químicos & 11 & Química \\
\hline 17 & Refino do Petróleo & & \\
\hline 18 & Químicos Diversos & & \\
\hline 19 & Farmacêutica e Perfumaria & 12 & Indústria Farmacêutica e de Perfumaria \\
\hline 20 & Artigos de Plástico & 13 & Indústria de Artigos de Plástico \\
\hline 21 & Indústria Têxtil & 14 & Indústria Têxtil \\
\hline 22 & Artigos do Vestuário & 15 & Vestuário, Calçados, Couros e Peles \\
\hline 23 & Fabricação de Calçados & & \\
\hline 24 & Indústria do Café & 16 & Indústria do Café \\
\hline 25 & Beneficiamento de Produtos Vegetais & 17 & Beneficiamento de Produtos Vegetais \\
\hline 26 & Abate de Animais & 18 & Abate de Animais \\
\hline 27 & Indústria de Laticínios & 19 & Indústria de Laticínios \\
\hline 28 & Indústria de Açúcar & 20 & Fabricação de Açúcar \\
\hline 29 & Fabricação de Óleos Vegetais & 21 & Fabricação de Óleos Vegetais \\
\hline 30 & Outros Produtos Alimentares & 22 & Fabricação de Outros Produtos Alimentares \\
\hline 31 & Indústrias Diversas & 23 & Indústrias Diversas \\
\hline 32 & Serviços Industriais de Utilidade Pública & 24 & Serviços Industriais de Utilidade Pública \\
\hline 33 & Construção Civil & 25 & Construção Civil \\
\hline 34 & Comércio & 26 & Comércio \\
\hline 35 & Transporte & 27 & Transporte \\
\hline 36 & Comunicações & 28 & Comunicações \\
\hline 37 & Instituições Financeiras & 29 & Instituições Financeiras \\
\hline 38 & Aluguel de Imóveis & 30 & Aluguel de Imóveis \\
\hline 39 & Administração Pública & 31 & Administração Pública \\
\hline 40 & Serviços Prestados às Famílias & 32 & Outros Serviços \\
\hline 41 & Serviços Prestados às Empresas & & \\
\hline 42 & Serviços Privados não Mercantis & & \\
\hline
\end{tabular}

Fonte: Rodrigues (2000).

A metodologia adotada para estimar a série de matrizes usada neste artigo parte do método do coeficiente locacional, e usa as matrizes do Brasil de 1980, 1985, 1990 e 1995; a matriz do Brasil de 1999, estimada por Guilhoto e Sesso Filho (2005); dados das Contas Nacionais, e informações 
da PIA (Pesquisa Industrial Anual), PAServiço e PAComércio. ${ }^{1}$ Esse procedimento torna possível a análise proposta.

\subsection{As ligações industriais e os setores-chave}

A análise das relações intersetoriais de dada economia está fundamentada no fato de que os produtos podem ser usados tanto pelas indústrias (produtos intermediários) quanto pelos consumidores para atender às necessidades da demanda final. Considerando que, no modelo de insumoproduto, a demanda final é autônoma, se torna possível determinar a quantidade a ser produzida em cada setor e a intensidade relativa dos efeitos nas diferentes indústrias, ou seja, as ligações intersetoriais.

Na literatura, estão registrados vários métodos que objetivam medir as ligações intersetoriais com o intuito de identificar setores-chave, na definição de Rasmussem (1956) e Hirschman (1958), ou pólos de crescimento, na visão de Perroux (1977) e Myrdal (1957). Recentemente, o conceito de 'ligações' tem atraído considerável interesse como meio de identificar setores-chave para a promoção de estratégias de desenvolvimento industrial. Acredita-se que a concentração de recursos, especialmente capital e habilidade empresarial, em setores-chave, possa permitir o crescimento mais rápido do produto e do emprego do que se fossem alocados em outros setores (McGilvray, 1977).

Embora exista consenso no que se refere à importância das ligações intersetoriais na determinação de estímulos ao crescimento econômico e no tocante ao fato de que o processo de transformação econômica é, freqüentemente, estimulado por um número relativamente pequeno de setores, parece haver pouco acordo com relação à identificação de setores-chave. Para McGilvray (1977), os fatores que desempenham papel dominante no processo de desenvolvimento dos países, como padrões de comércio e competitividade internacionais, disponibilidade de recursos naturais, habilidade/talento empresarial e tecnologia, não são explicitamente reconhecidos quando se busca a determinação de setores-chave. Segundo Guilhoto et al. (1994), parte da confusão deve-se à dificuldade de se identificar quais seriam os setores que contribuem acima da média para a economia, tanto numa perspectiva ex-post quanto ex-ante.

Partindo da proposta de Guilhoto et al. (1994) de considerar os vários métodos existentes para medir os índices de ligações como complementares na análise de determinada economia, o que permitiria determinar os setores-chave de forma mais equilibrada e ampla, e considerando os índices de ligações que podem ser derivados das tabelas de insumo-produto como um primeiro passo na identificação de áreas potenciais de projetos de desenvolvimento (McGilvray, 1977), são expostos, nesta seção, os métodos usados para identificar os setores que mais dinamizaram a economia paranaense nos anos estudados.

\subsubsection{Os índices de Rasmussen-Hirschman}

Os índices de ligações de Rasmussen-Hirschman têm sido muito aplicados e comentados na literatura por McGilvray (1977), Hewings (1982), Guilhoto et al. (1994), dentre outros. Essas medidas, inicialmente idealizadas por Rasmussen (1956), foram usadas como meio de identificar setores-chave por Hirschman (1958).

Considerando a estrutura interna da economia baseada no modelo de insumo-produto e seguindo os dois últimos autores, é possível determinar os setores que teriam o maior poder de encadeamento dentro da economia, isto é, realizar o cálculo dos índices de ligações para trás, que

1 Para detalhes sobre a metodologia de estimação das matrizes insumo-produto para o Paraná para os anos de 1980, 1985, 1990 e 1995, ver Rodrigues (2000), e para 1999, ver Parré e Alves (2002). 
estimam o quanto um setor demanda dos outros setores, e os índices de ligações para frente, que informam o quanto um setor é demandado pelos outros.

Desse modo, com base na equação $L=(I-A)^{-1}$, define-se $l_{i j}$ como um elemento da matriz inversa de Leontief, $L, L^{*}$ como a média de todos os elementos de $L$ e $L_{\bullet j}$ e $L_{i \bullet}$ como a soma dos elementos de uma coluna e de uma linha típica de $L$, dada, respectivamente, como

$$
L_{\bullet j}=\sum_{i=1}^{n} l_{i j} \text { e } L_{i \bullet}=\sum_{j=1}^{n} l_{i j} \quad i, j=1,2, \ldots n
$$

Assim:

Índices de ligações para trás (poder de dispersão):

$$
U_{j}=\left[L_{\bullet j} / n\right] / L^{*}
$$

Índices de ligações para frente (sensibilidade da dispersão):

$$
U_{i}=\left[L_{i \bullet} / n\right] / L^{*}
$$

Para Rasmussen e Hirschman, valores maiores do que 1, tanto dos índices de ligações para trás quanto para frente, indicam setores acima da média e, portanto, considerados setores-chave para o crescimento da economia.

\subsubsection{O campo de influência}

Apesar de os índices de ligações de Rasmussen-Hirschman avaliarem a importância dos setores em termos de seus impactos no sistema como um todo, dificultam a visualização dos principais elos de ligações dentro da economia, isto é, de quais seriam os coeficientes que, se alterados, teriam um maior impacto no sistema como um todo. Visando superar esse problema de modo a verificar como se distribui a influência de cada setor sobre os demais setores da economia, utiliza-se o enfoque do campo de influência desenvolvido por Sonis e Hewings (1989 e 1994).

O conceito de campo de influência mostra como se distribuem as mudanças dos coeficientes diretos no sistema econômico como um todo, permitindo a determinação de quais relações entre os setores seriam mais importantes dentro do processo produtivo. Desse modo, o conceito de campo de influência se apresenta como uma análise complementar a dos índices de ligações de Rasmussen-Hirschman, uma vez que os principais elos de ligação dentro da economia vão ocorrer nos setores que apresentam os maiores índices de ligações, tanto para frente como para trás.

O procedimento para o cálculo do campo de influência requer a matriz de coeficientes técnicos de produção, $A=\left|a_{i j}\right|$, e uma matriz de variações incrementais nos coeficientes diretos de insumo, $E=\left|\varepsilon_{i j}\right|$. As correspondentes matrizes inversas de Leontief são dadas por $L=[I-A]-1=$ $\left|l_{i j}\right|$ e por $L(\varepsilon)=[\mathrm{I}-(\mathrm{A}+\varepsilon)]-1=\left|l_{j i}(\varepsilon)\right|$. De acordo com Sonis e Hewings (1989 e 1994), caso a variação seja pequena e só ocorra num coeficiente direto, isto é:

$$
\varepsilon_{i j}=\left\{\begin{array}{cc}
\varepsilon & i=i_{1}, j=j_{1} \\
0 & i \neq i_{1} \text { ou } j \neq j_{1}
\end{array}\right.
$$

o campo de influência desta variação pode ser aproximado pela expressão:

$$
F\left(\varepsilon_{i j}\right)=\frac{\left[L\left(\varepsilon_{i j}\right)-L\right]}{\varepsilon_{i j}}
$$


em que $\mathrm{F}\left(\varepsilon_{i j}\right)$ é a matriz $(n \times n)$ do campo de influência do coeficiente $a_{i j}$.

Para determinar quais coeficientes possuem o maior campo de influência, associa-se a cada matriz $\mathrm{F}\left(\varepsilon_{i j}\right)$ um valor que é dado por:

$$
S_{i j}=\sum_{k=l}^{n} \sum_{l=1}^{n}\left[f_{k l}\left(\varepsilon_{i j}\right)\right]^{2}
$$

Desse modo, os coeficientes diretos que possuem os maiores valores de $S_{i j}$ serão aqueles com os maiores campos de influência dentro da economia como um todo.

\subsubsection{Abordagem GHS: os índices puros de ligação}

Os índices de ligações de Rasmussen-Hirschman, embora largamente utilizados na literatura, são criticados por não levar em consideração os diferentes níveis de produção em cada setor da economia. Com o intuito de corrigir essa deficiência, foi proposto, inicialmente, o enfoque Cella-Clements (Cella, 1984 e Clements, 1990), posteriormente a visão do índice puro de ligações (Guilhoto et al., 1994) e, mais recentemente, a abordagem do novo índice puro de ligações, também denominada GHS (Guilhoto et al., 1996). ${ }^{2}$

O novo índice puro de ligações, daqui por diante denominado de GHS, será utilizado neste estudo por permitir identificar os graus dos impactos na demanda final em determinadas regiões ou setores, bem como dimensionar as interações entre setores e regiões em termos de valor da produção.

Partindo da consolidação da abordagem GHS apresentada em Guilhoto et al. (1996), a matriz de coeficientes de insumos diretos, $A$, representando um sistema de insumo-produto para duas regiões, $j$ e $r$ é dada por:

$$
A=\left(\begin{array}{cc}
A_{j j} & A_{j r} \\
A_{r j} & A_{r r}
\end{array}\right)
$$

em que $A_{j j}$ e $A_{r r}$ são matrizes quadradas dos insumos diretos dentro da primeira e da segunda regiões, respectivamente; $A_{r j}$ e $A_{j r}$ e representam matrizes retangulares mostrando os insumos diretos comprados pela primeira região e vice-versa.

Da equação (2.7) chega-se a:

$$
L=(I-A)^{-1}=\left(\begin{array}{cc}
L_{j j} & L_{j r} \\
L_{r j} & L_{r r}
\end{array}\right)=\left(\begin{array}{cc}
\Delta_{j j} & 0 \\
0 & \Delta_{r r}
\end{array}\right)\left(\begin{array}{cc}
\Delta_{j} & 0 \\
0 & \Delta_{r}
\end{array}\right)\left(\begin{array}{cc}
I & A_{j r} \Delta_{r} \\
A_{r j} \Delta_{j} & I
\end{array}\right)
$$

cujos elementos são definidos como:

$$
\begin{aligned}
& \Delta_{j}=\left(I-A_{j j}\right)^{-1} \\
& \Delta_{r}=\left(I-A_{r r}\right)^{-1} \\
& \Delta_{j j}=\left(I-\Delta_{j} A_{j r} \Delta_{r} A_{r j}\right)^{-1}
\end{aligned}
$$

2 Para uma evolução cronológica das várias abordagens de índices de ligações anteriores ao GHS e algumas aplicações à economia brasileira, ver Guilhoto et al. (1994) e Clements e Rossi (1991 e 1992). 


$$
\Delta_{r r}=\left(I-\Delta_{r} A_{r j} \Delta_{j} A_{j r}\right)^{-1}
$$

Pela decomposição de (2.8), é possível verificar como ocorre o processo de produção na economia, bem como derivar uma série de multiplicadores e de ligações da estrutura produtiva. Assim, a matriz

$$
\left[\begin{array}{cc}
\Delta_{j j} & 0 \\
0 & \Delta_{r r}
\end{array}\right]
$$

pode ser interpretada como o multiplicador externo de Miyazawa (1976) para a região $j$ e a região $r$, enquanto a matriz

$$
\left[\begin{array}{cc}
\Delta_{j} & 0 \\
0 & \Delta_{r}
\end{array}\right]
$$

representa o multiplicador interno de Miyazawa (1976) para a região $j$ e a região $r$.

Na matriz

$$
\left[\begin{array}{cc}
I & A_{j r} \Delta_{r} \\
A_{r j} \Delta_{j} & I
\end{array}\right]
$$

a primeira linha separa a demanda final pela sua origem, isto é, diferencia a demanda final interna da região $(I)$ da demanda final externa da região $\left(A_{j r} \Delta_{r}\right)$. A mesma idéia aplica-se à segunda linha.

Conjugando a equação (2.8) com a formulação de Leontief dada por:

$$
X=(I-A)^{-1} Y
$$

é possível derivar um conjunto de índices que podem ser usados para

a) ordenar as regiões em termos de sua importância no valor da produção gerado e

b) verificar como ocorre o processo de produção na economia.

Esses índices são obtidos de:

$$
\left(\begin{array}{c}
X_{j} \\
X_{r}
\end{array}\right)=\left(\begin{array}{cc}
\Delta_{j j} & 0 \\
0 & \Delta_{r r}
\end{array}\right)\left(\begin{array}{cc}
\Delta_{j} & 0 \\
0 & \Delta_{r}
\end{array}\right)\left(\begin{array}{cc}
I & A_{j r} \Delta_{r} \\
A_{r j} \Delta_{j} & I
\end{array}\right)\left(\begin{array}{c}
Y_{j} \\
Y_{r}
\end{array}\right)
$$

Fazendo o produto dos três últimos termos do lado direito da equação (2.17), chega-se a:

$$
\left(\begin{array}{c}
X_{j} \\
X_{r}
\end{array}\right)=\left(\begin{array}{cc}
\Delta_{j j} & 0 \\
0 & \Delta_{r r}
\end{array}\right)\left(\begin{array}{c}
\Delta_{j} Y_{j}+\Delta_{j} A_{j r} \Delta_{r} Y_{r} \\
\Delta_{r} A_{r j} \Delta_{j} Y_{j}+\Delta_{r} Y_{r}
\end{array}\right)
$$

em que $A_{j r} \Delta_{r} Y_{r}$ é o impacto direto da demanda final da região $r$ sobre a região $j$, isto é, fornece o nível de exportação da região $j$ necessário para satisfazer o nível de produção da região $r$ dada uma demanda final $Y_{r}$ e $A_{r j} \Delta_{j} Y_{j}$ é o impacto direto da demanda final da região $j$ sobre a região $r$, ou seja, indica o nível de exportações da região $r$ que é necessário para satisfazer a necessidade de produção da região $j$ para uma determinada demanda final $Y_{j}$. 
A partir de (2.18) podem ser extraídas as novas definições de índice puro de ligação para trás $(P B L)$ e de índice puro de ligação para frente $(P F L)$ dadas por:

$$
\begin{aligned}
& P B L=\Delta_{r} A_{r j} \Delta_{j} Y_{j} \\
& P F L=\Delta_{j} A_{j r} \Delta_{r} Y_{r}
\end{aligned}
$$

O PBL representa o impacto puro do valor da produção total da região $j$ sobre a região $r$, $\left(\Delta_{j} Y_{j}\right)$, ou seja, o impacto que é livre da demanda de insumos que a região $j$ realiza da própria região $j$ e dos retornos da região $r$ para a região $j$ e vice-versa. O PFL indica o impacto puro do valor da produção total da região r sobre a região $j,\left(\Delta_{r} Y_{r}\right)$. Uma vez que o $P B L$ e o $P F L$ são expressos em valores correntes, o índice puro do total das ligações $(P T L)$ de cada setor na economia pode ser obtido pela adição de ambos:

$$
P T L=P B L+P F L
$$

Por fim, multiplicando-se os dois termos do lado direito de (2.18) tem-se:

$$
\left(\begin{array}{c}
X_{j} \\
X_{r}
\end{array}\right)=\left(\begin{array}{l}
\Delta_{j j} \Delta_{j} Y_{j}+\Delta_{j j} \Delta_{j} A_{j r} \Delta_{r} Y_{r} \\
\Delta_{r r} \Delta_{r} A_{r j} \Delta_{j} Y_{j}+\Delta_{r r} \Delta_{r} Y_{r}
\end{array}\right)=\left(\begin{array}{c}
X_{j}^{j}+X_{j}^{r} \\
X_{r}^{j}+X_{r}^{r}
\end{array}\right)
$$

O total da produção da região $j(X j)$, representado em $(2.22)$, pode ser dividido em dois componentes:

$$
\begin{aligned}
& X_{j}^{j}=\Delta_{j j} \Delta_{j} Y_{j} \\
& X_{j}^{r}=\Delta_{j j} \Delta_{j} A_{j r} \Delta_{r} Y_{r}
\end{aligned}
$$

em que o $X_{j}^{j}$ fornece o nível total de produção da região $j$ que é devido à demanda final da região $j$ e $X_{j}^{r}$ quantifica o nível de produção total da região $j$ proporcionado pela demanda final da região $r$. Da mesma forma, o nível total de produção da região $r$ pode, também, ser separado em dois componentes:

$$
\begin{aligned}
& X_{r}^{j}=\Delta_{r r} \Delta_{r} A_{r j} \Delta_{j} Y_{j} \\
& X_{r}^{r}=\Delta_{r r} \Delta_{r} Y_{r}
\end{aligned}
$$

em que o $X_{r}^{j}$ fornece o nível total de produção da região $r$ que é devido à demanda final da região $j$ e $X_{r}^{r}$ quantifica o nível de produção total da região $r$ proporcionado pela demanda final da região $r$.

Esta metodologia fornece um poderoso instrumental analítico, tendo em vista a integração dos principais métodos usados, possibilitando, desta forma, a decomposição dos impactos entre as diferentes regiões, além de permitir a análise da economia, dada a sua estrutura produtiva. 


\subsection{Multiplicadores de produção}

Os multiplicadores complementam a análise da importância de determinado setor na economia, na medida em que são instrumentos úteis empregados na verificação de impactos sobre determinado sistema econômico resultante de choques nos elementos exógenos, a curto ou longo prazo. O emprego dos multiplicadores permite verificar os efeitos de políticas públicas sobre a produção total da economia ou sobre outras variáveis como o nível de emprego e a renda.

Qualquer que seja o tipo de análise e o prazo considerado, o modelo de insumo-produto para análise de impacto ou previsão segue a forma geral $X=(I-A)^{-1} Y$, em que $X$ é o valor da produção, $(I-A)^{-1}=L$ é matriz inversa de Leontief e $Y$ é a demanda final (Miller e Blair, 1985).

Os multiplicadores freqüentemente mais utilizados são os de produção, renda e emprego. ${ }^{3}$

Nesse estudo serão apresentados os multiplicadores de produção, os quais permitem determinar o impacto de variações na demanda final sobre o volume de produção. O multiplicador de produção simples para o setor $j$ é definido como o valor total da produção, em todos os setores da economia, que é necessário para satisfazer o aumento de uma unidade monetária de demanda final pela produção do setor $j$.

Em geral, o multiplicador de produção simples $\left(P_{j}\right)$ para o setor $j$, é dado por:

$$
P_{j}=\sum_{i=l}^{n} l_{i j}
$$

em que $l_{i j}$ representa os elementos da matriz inversa de Leontief.

\section{ReSUltados E DisCUSSÃO}

\subsection{Ligações industriais e setores-chave na economia do Paraná e do restante do Brasil}

\subsubsection{Os índices de Rasmussen-Hirschman}

A Tabela 2 mostra os resultados dos índices de ligações de Rasmussen-Hirschman para o Paraná nos anos e setores estudados, bem como a ordem de importância dos mesmos na economia.

Uma visão panorâmica da Tabela 2 permite destacar que somente Celulose, Papel e Gráfica (9) permaneceu como setor-chave para o crescimento da economia paranaense, levando em conta o conceito restrito, ou seja, aquele que apresenta, simultaneamente, índices de ligações para frente e para trás maiores do que 1. Os setores Química (11) e Indústria Têxtil (14), ambos componentes da indústria de transformação, foram setores-chave em anos distintos, o primeiro em 1999 e o segundo nos anos anteriores.

Entretanto, a evolução do perfil da estrutura produtiva paranaense pode ser melhor caracterizada considerando a definição menos restrita de setores-chave, segundo a qual índices para frente ou para trás maiores do que 1 indicam setores dinâmicos e, portanto, importantes para o crescimento da economia. Dentro dessa perspectiva, o Paraná apresentou, além dos setores assinalados anteriormente, 18 setores-chave em 1980 (12 com ligações para trás e 6 com ligações para frente), 18 em 1985 (12 com ligações para trás e 6 com ligações para frente), 18 em 1990 (11 com ligações para trás e 7 com ligações para frente), 18 em 1995 (12 com ligações para trás e 6 com ligações para frente) e 15 em 1999 (10 com ligações para trás e 5 com ligações para frente).

3 Nesta seção são descritos apenas os multiplicadores simples. Para outros tipos de multiplicadores, ver Miller e Blair (1985). 


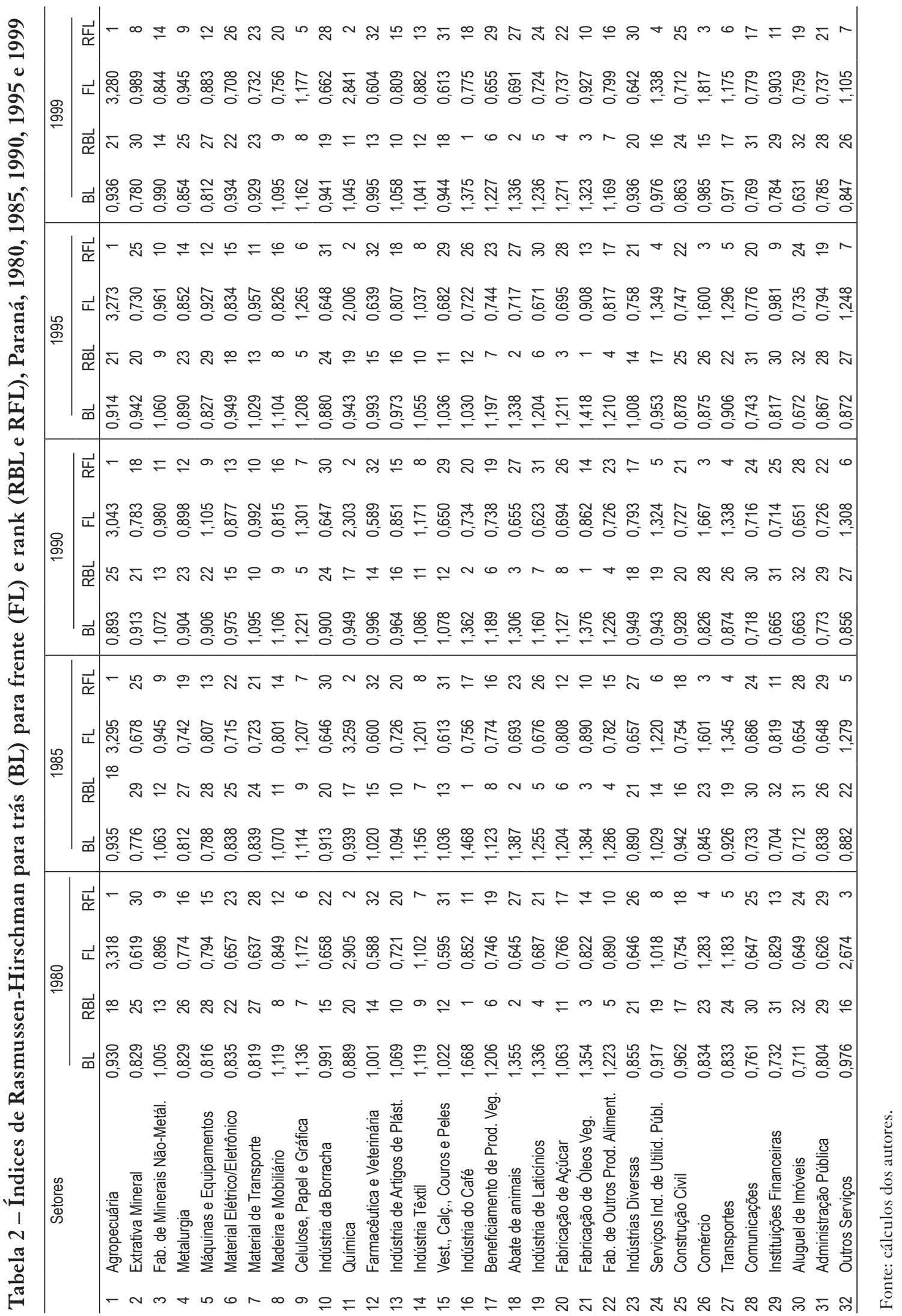


Essas informações evidenciaram as seguintes características da economia paranaense no período de 1980-1999:

a) a conjugação de índices de ligações para trás elevados em todos os setores alimentares (16 a 22) com índices de ligações para frente mais elevados nos setores Agropecuária (1), Química (11) e Serviços $(24,26,27$ e 32) permite afirmar que o Paraná possuía uma indústria pouco diversificada, centrada nas indústrias produtoras de alimentos e na agropecuária enquanto fornecedora de matérias-primas;

b) o número de setores com ligações para trás foi o dobro do número de setores com ligações para frente, evidenciando que são aceitáveis políticas que objetivem estimular a demanda por insumos intermediários, notadamente se essa demanda for atendida por insumos domésticos;

c) o comportamento dos índices de ligações para trás dos setores alimentares aponta na direção de queda da importância dos mais tradicionais enquanto setores indutores do crescimento da economia estadual;

d) por outro lado, os setores alimentares mais modernos ou com novas atividades registraram menor decréscimo ou manutenção de seu dinamismo, a exemplo de Abate de Animais (18), Indústria de Laticínios (19), Fabricação de Açúcar (20) e Fabricação de Óleos Vegetais (21) e Fabricação de Outros Produtos Alimentares (22);

e) outros setores da indústria de transformação, tais como Metalurgia (4), Máquinas e Equipamentos (5), Material Elétrico/Eletrônico (6) e Material de Transporte (7) parecem emergir na economia paranaense, delineando uma tendência futura de maior diversificação industrial;

f) os setores do ramo Serviços ganham importância para o crescimento da economia estadual.

O tamanho dos índices de ligações é um indicador da capacidade dos setores em dinamizar a economia. Com base na Tabela 2 e considerando os três maiores índices de ligações para frente, observa-se que a oferta de insumos se processou pelos setores Agropecuária (1), Química (11) e Outros Serviços (32) em 1980. Nos outros anos estudados, essa combinação alterou-se pouco, com a substituição do setor (32) pelo setor Comércio (26).

Por outro lado, levando em conta os maiores índices de ligações para trás, a maioria deles está relacionada aos setores vinculados à Indústria Alimentar para todo o período analisado, revelando que esses concentraram a demanda por insumos para o processamento industrial no Paraná.

\subsubsection{O campo de influência}

Para complementar a análise dos índices de ligações de Rasmussen-Hirschman e detectar como se distribuem as alterações dos coeficientes diretos no sistema econômico como um todo, foi calculado o campo de influência.

Assim, as relações intersetoriais mais importantes dentro do processo produtivo da economia paranaense nos anos em tela podem ser vistas nas Figuras 1 a 5, onde são apresentados os 50 coeficientes setoriais com maior campo de influência.

Em 1980, se pequenas mudanças nos coeficientes diretos de produção ocorressem, as relações comerciais da Indústria do Café (16) seriam as grandes propagadoras dessas alterações no sistema, apresentando 12 coeficientes relativos à venda. Certamente, a importância desempenhada pelo café na economia paranaense na década de 1980 pode ser vista como principal razão desse comportamento (Figura 1).

4 Ver Rodrigues et al. (2002) e Rodrigues e Guilhoto (2004) para análise detalhada do período 1980-1995. 
Figura 1 - Coeficientes setoriais com maior campo de influência, Paraná, 1980

Setores Compradores

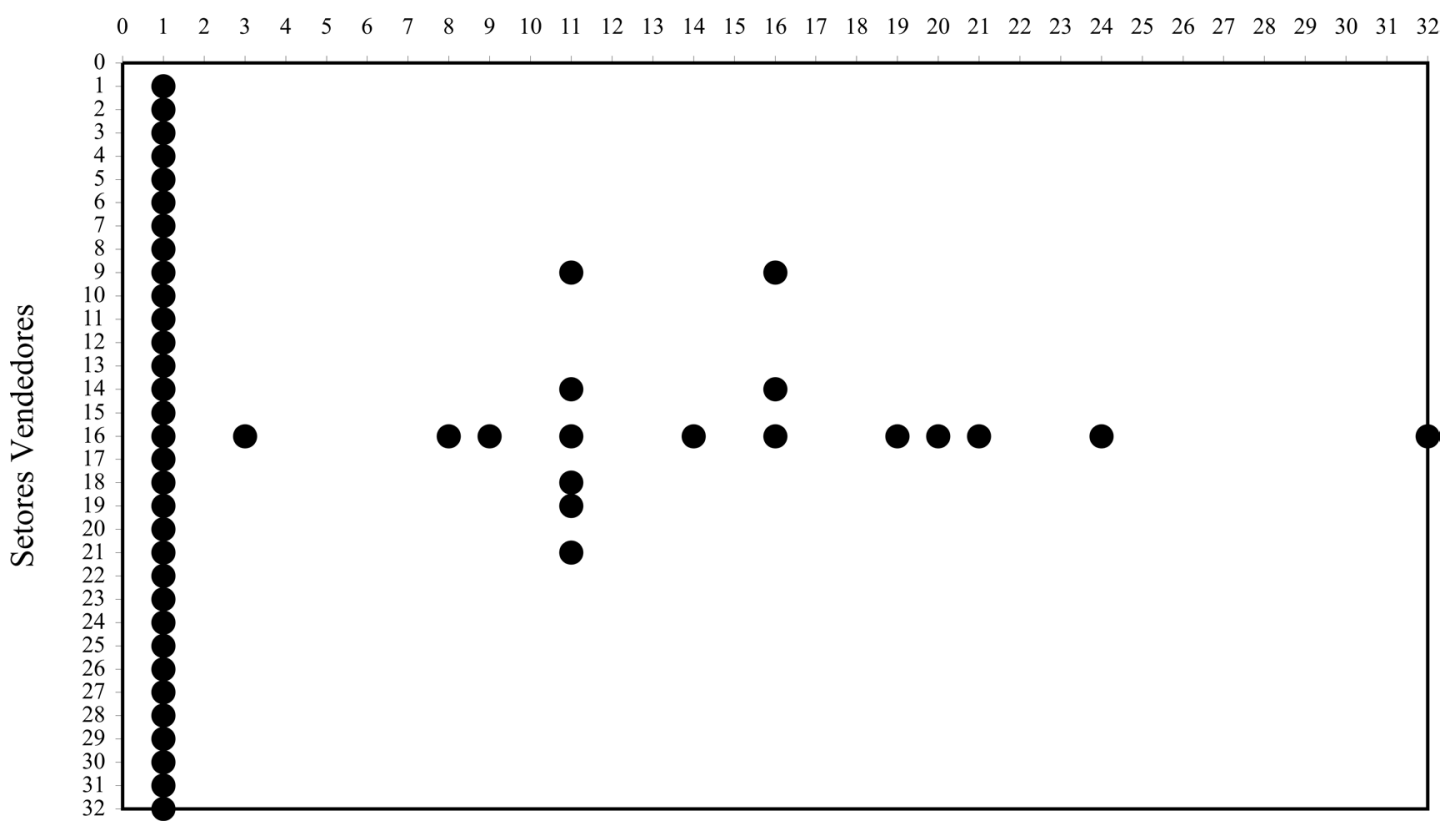

A Figura 2 revela que, em 1985, os principais elos de ligações da economia são dominados pelos setores Têxtil (14) e Serviços Industriais de Utilidade Pública (24), ambos com 4 coeficientes relativos a vendas para outros setores e 6 e 4 coeficientes, respectivamente, envolvendo compras de seus produtos.

Figura 2 - Coeficientes setoriais com maior campo de influência, Paraná, 1985

Setores Compradores

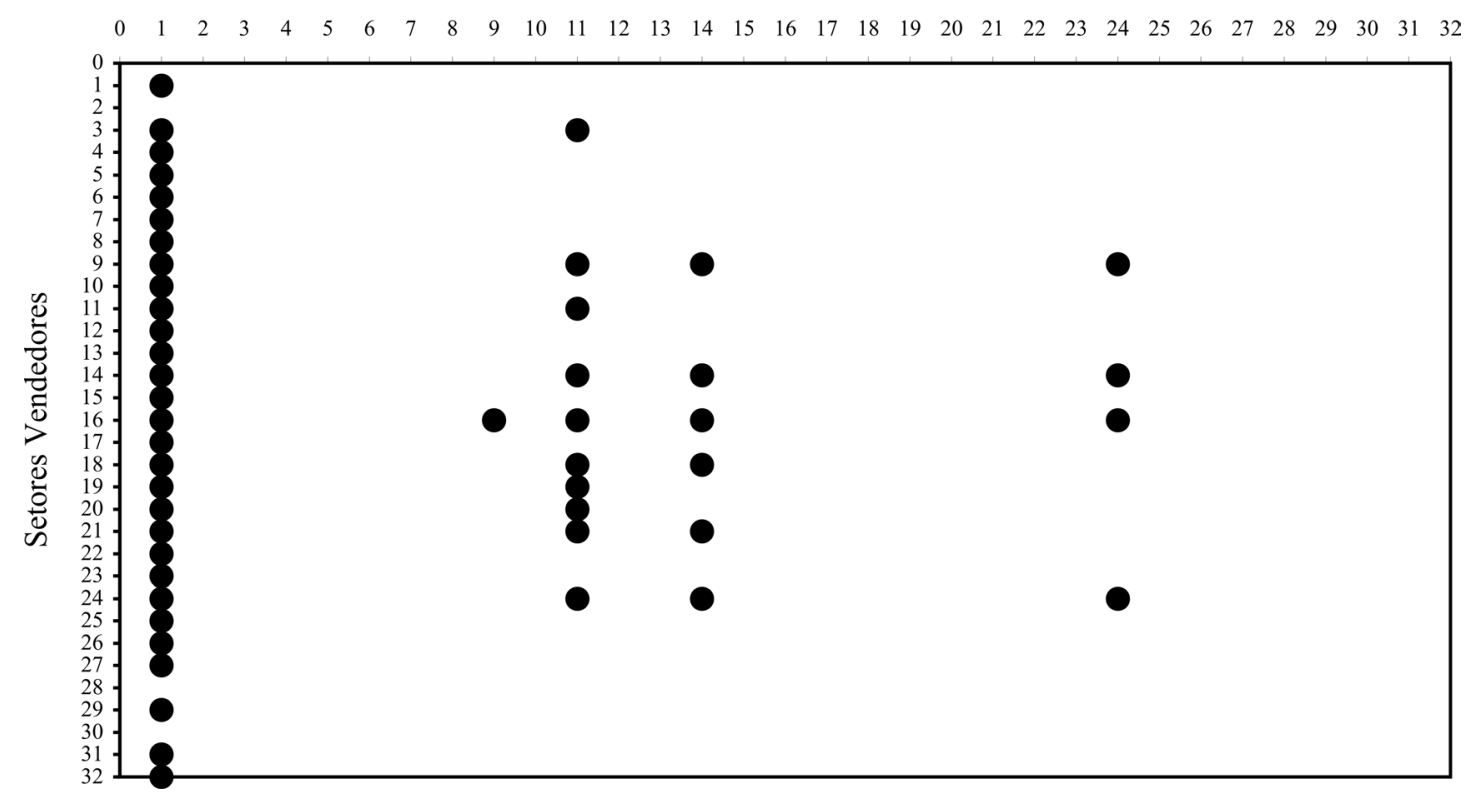


Em 1990, intensificam-se as relações tanto de compra quanto de venda entre os setores da indústria de transformação, merecendo destaque as dos setores Material de Transporte (7) e Celulose, Papel e Gráfica (9). No segmento Serviços, o setor (24) continuou apresentando os maiores elos de ligações, embora com menor magnitude relativamente a 1985 (Figura 3).

Figura 3 - Coeficientes setoriais com maior campo de influência, Paraná, 1990

Setores Compradores

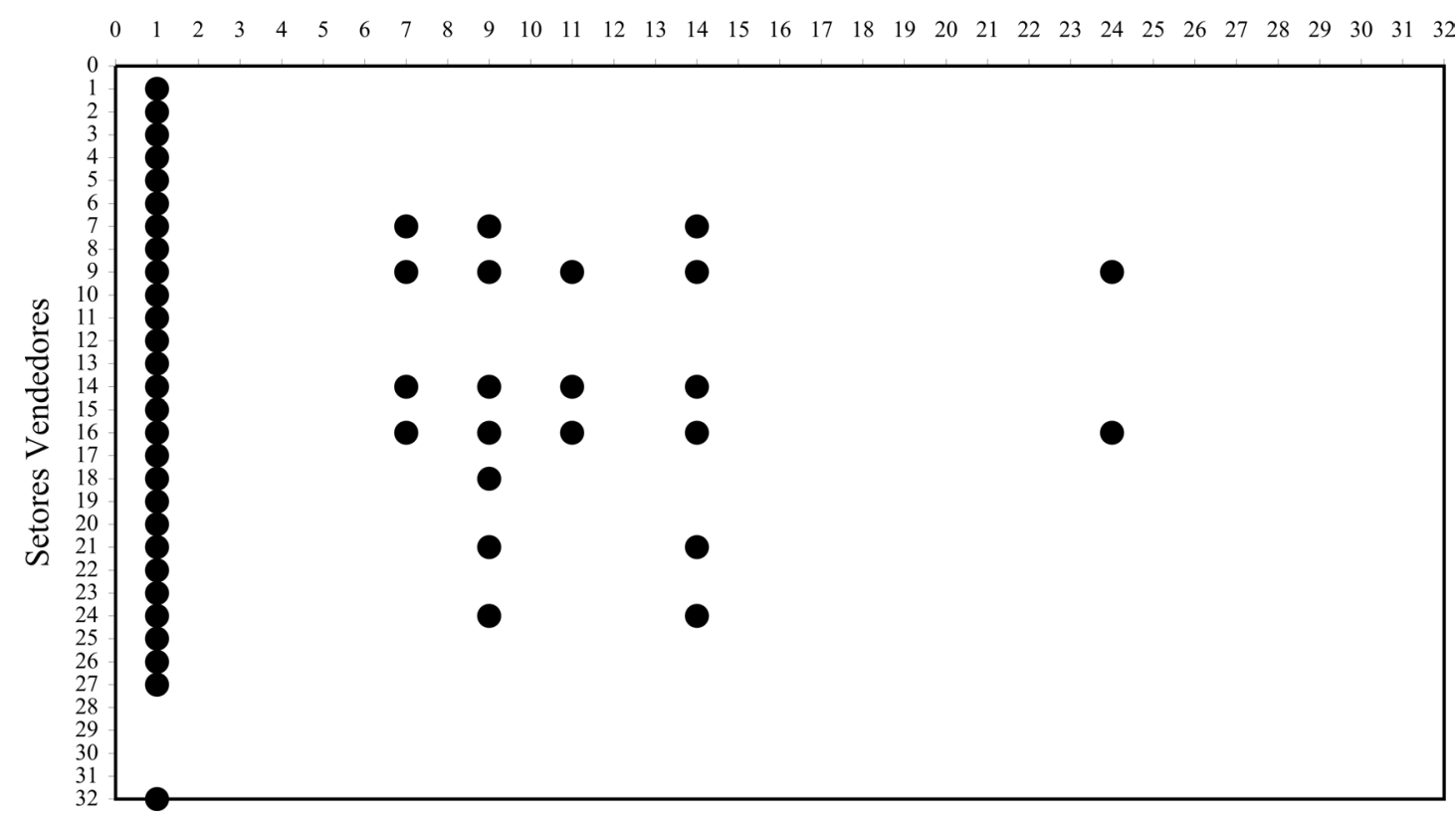

A exemplo de 1990, o ano de 1995 mostrou um cenário mais variado de setores responsáveis por maiores mudanças na economia. O setor dominante no ramo de transformação continuou a ser o (9), com 6 coeficientes envolvendo compras de outros setores e 6 envolvendo vendas de seus produtos a outros setores, enquanto no ramo Serviços permaneceu o setor (24) com 5 e 4 coeficientes, respectivamente. Destaca-se a entrada do setor Fabricação de Óleos Vegetais (21) como vendedor de insumos na economia em 1995 (Figura 4). 
Figura 4 - Coeficientes setoriais com maior campo de influência, Paraná, 1995

Setores Compradores

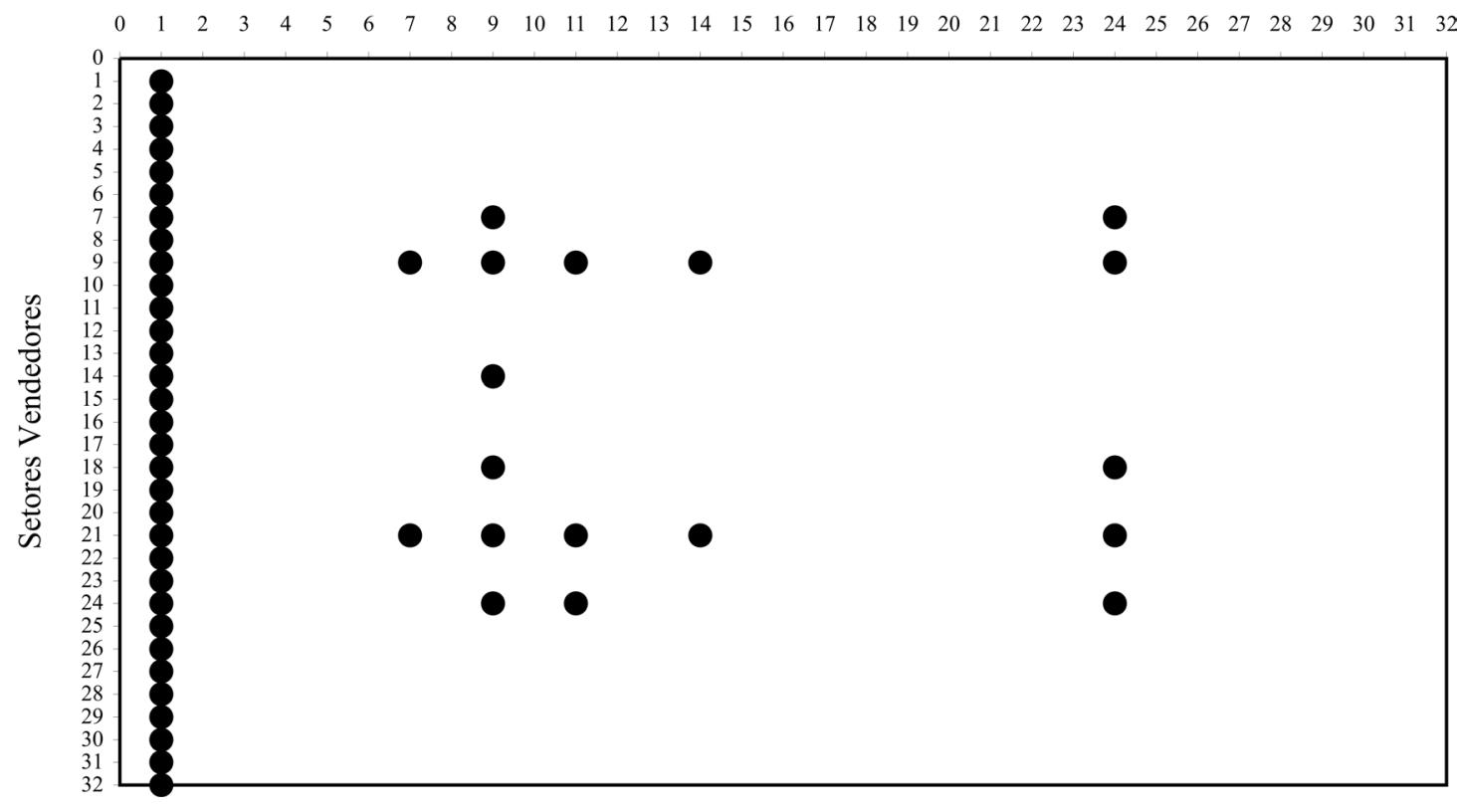

O ano de 1999 reforça a importância dos setores (1), (11) e (24) notadamente como compradores dos outros setores (Figura 5).

Figura 5 - Coeficientes setoriais com maior campo de influência, Paraná, 1999

Setores Compradores

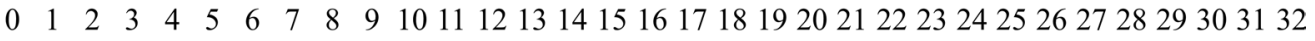

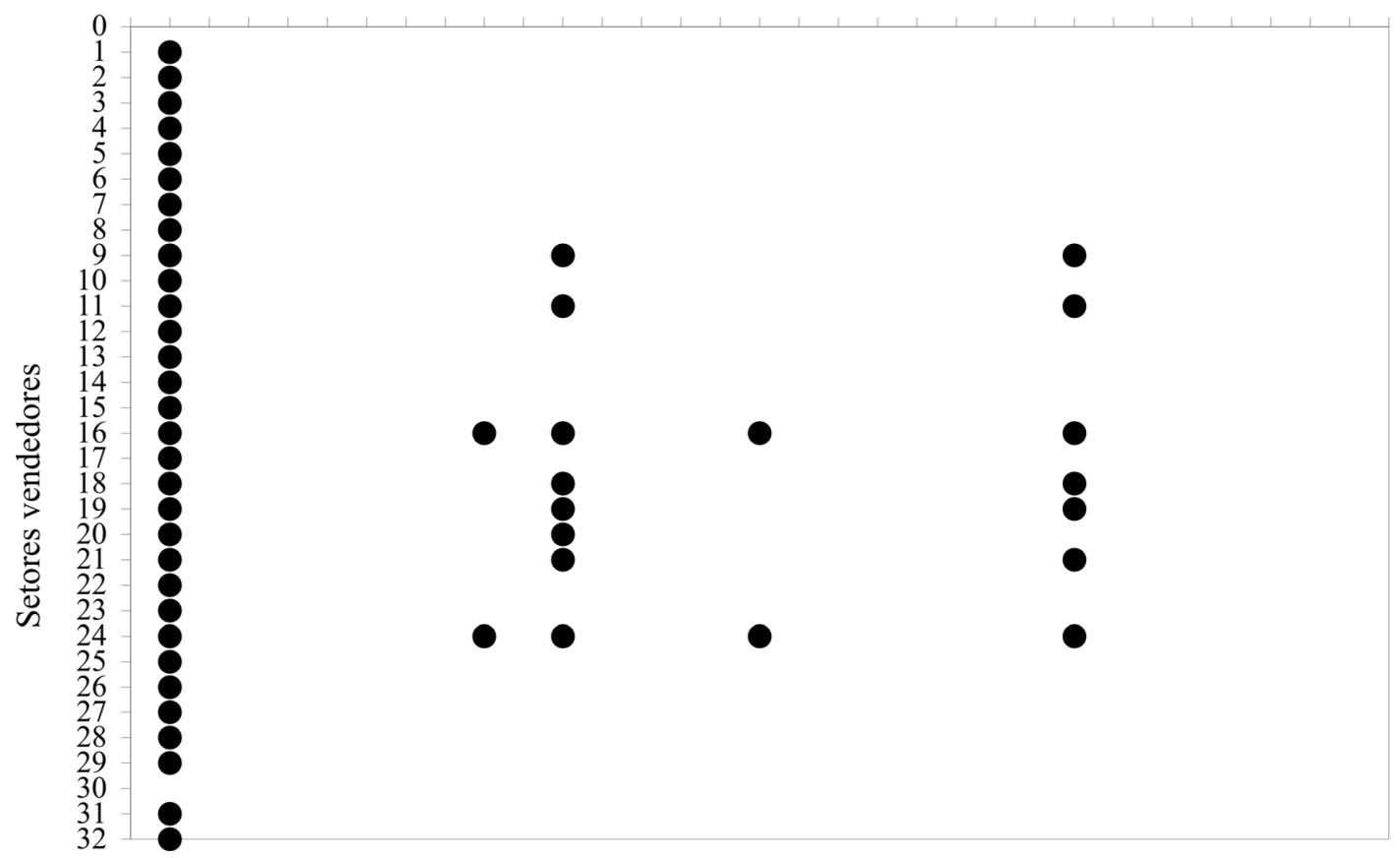


Para todo o período, considerando somente o lado das compras, cabe destacar o setor Agropecuária (1), seguido do setor Química (11). Assim, pode-se inferir que as relações de comercialização envolvendo ambos os setores podem gerar grande impacto sobre o resto da economia.

Nos anos 1980-1999, algumas tendências importantes puderam ser detectadas:

a) a economia paranaense apresentou-se mais interligada, com maior número de relações intersetoriais importantes dentro do processo produtivo;

b) essa diversificação ocorreu com maior intensidade no segmento de transformação;

c) o setor Agropecuária continuou sendo o mais importante comprador de insumos na economia estadual;

d) as relações de comércio envolvendo os setores (11), (14) e (24) nos anos de 1980 e 1985, os setores (7), (9), (14) e (24) em 1990 e 1995, os setores (11) e (24) em 1999 e o setor (1) nesses cinco anos tiveram profundo efeito no resto da economia.

\subsubsection{Os índices puros de ligação}

Os índices puros relativos de ligação intersetoriais para frente, para trás e total para o Paraná estão apresentados na Tabela 3 e objetivam medir a importância de dado setor para a economia em termos do seu valor da produção. Esses índices são apresentados em termos relativos de modo a facilitar comparações entre os anos estudados.

Observa-se, com base no valor da produção gerado, que a importância dos setores para a economia estadual é relativamente diferenciada nesses anos (Tabela 3). Os setores que apresentaram maiores índices puros de ligações para trás nos anos 80 foram Agropecuária (1), Madeira e Mobiliário (8), alguns setores componentes da indústria alimentar (16, 17, 21 e 22) e os relacionados ao ramo serviços $(25,26,31$ e 32$)$.

Esses setores se caracterizam como grandes demandantes na economia. Em outras palavras, isso significa que, em valor da produção, foram os que mais impactaram a economia estadual no período.

Entretanto, nota-se, da década de 1980 para a de 1990, mudança no sentido de maior participação dos setores do segmento serviços e menor participação da indústria alimentar, esta última entrando nos anos 90 com índices relativos para trás bastante reduzidos. Esta alteração na composição setorial revela a tendência, já detectada na economia paranaense, de maior crescimento dos setores do ramo serviços e menos crescimento da agropecuária e dos setores da indústria alimentar (Tabela 3).

Com relação aos índices puros de ligações para frente, para os anos 80 os destaques ficam com os setores Agropecuária (1), Fabricação de Minerais Não-Metálicos (3), Celulose, Papel e Gráfica (9), Química (11), Comércio (26), Transportes (27) e Outros Serviços (32).

Para os anos 90, a conformação setorial fica, praticamente, a mesma dos anos 80, cabendo registrar a presença crescente dos setores do segmento Serviços, com a entrada, a partir de 1985, do setor Serviços Industriais de Utilidade Pública (24). Assim, como os índices puros de ligações para frente registram setores altamente ofertantes ou muito demandados na economia, eles revelam, por conseqüência, o grande impacto puro da produção total da economia sobre estes setores. 


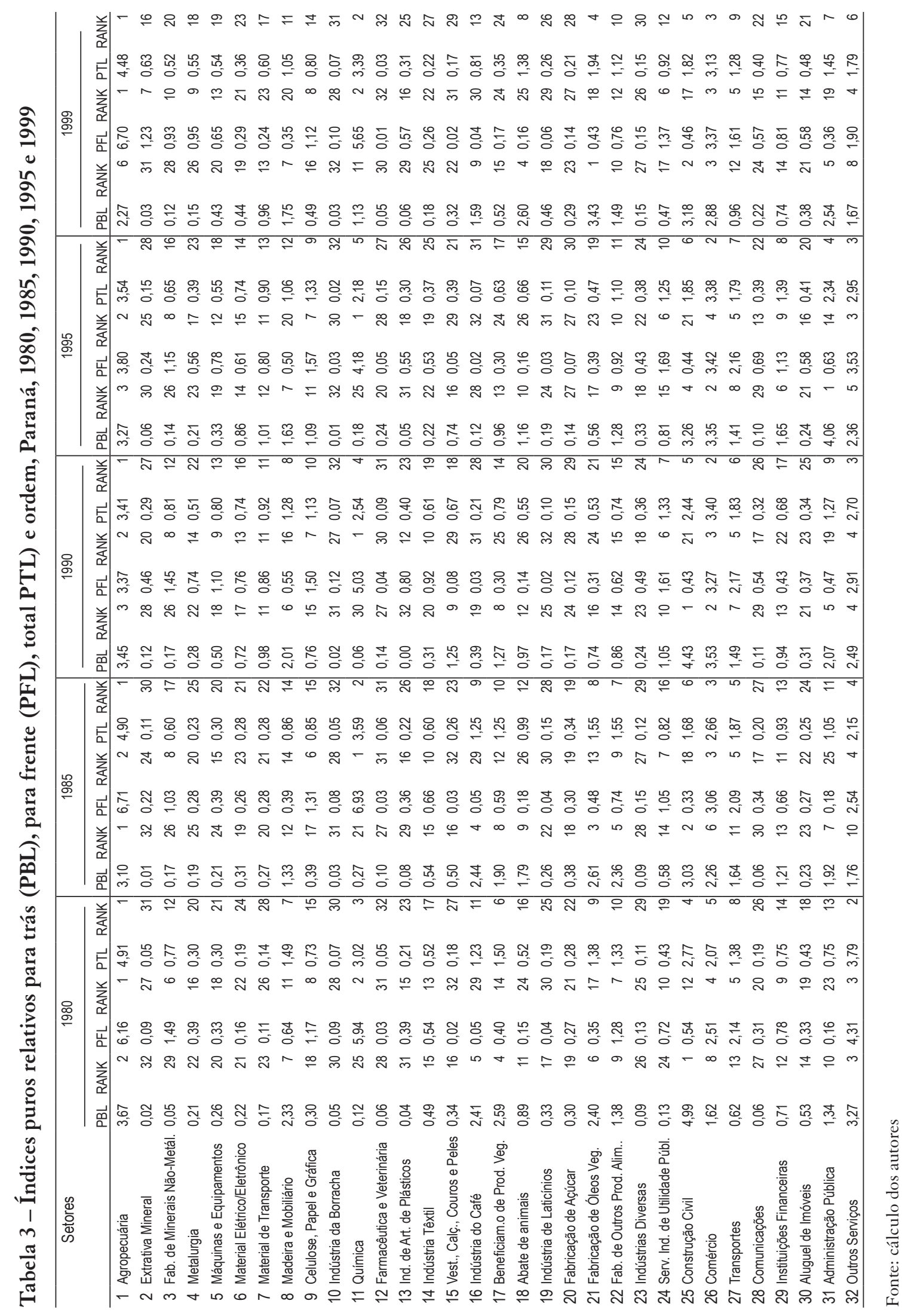




\subsection{Impacto da demanda final sobre a produção}

A Tabela 4 mostra a produção induzida pelo aumento de 1.000 unidades monetárias nas demandas finais dos setores, ao longo do período em análise.

Tabela 4 - Produção induzida pelo aumento de 1.000 unidades monetárias na demanda final, Paraná, 1980, 1985, 1990, 1995 e 1999 - em unidades monetárias*

\begin{tabular}{|c|c|c|c|c|c|}
\hline Setores & 1980 & 1985 & 1990 & 1995 & 1999 \\
\hline 1 Agropecuária & 1.615 & 1.592 & 1.549 & 1.456 & 1.563 \\
\hline 2 Extrativa Mineral & 1.440 & 1.320 & 1.584 & 1.499 & 1.303 \\
\hline 3 Fabricação de Minerais Não-Metálicos & 1.745 & 1.809 & 1.861 & 1.687 & 1.654 \\
\hline 4 Metalurgia & 1.439 & 1.382 & 1.568 & 1.417 & 1.427 \\
\hline 5 Máquinas e Equipamentos & 1.416 & 1.342 & 1.571 & 1.317 & 1.357 \\
\hline 6 Material Elétrico/Eletrônico & 1.451 & 1.427 & 1.691 & 1.511 & 1.560 \\
\hline 7 Material de Transporte & 1.423 & 1.428 & 1.901 & 1.639 & 1.553 \\
\hline 8 Madeira e Mobiliário & 1.943 & 1.822 & 1.919 & 1.758 & 1.829 \\
\hline 9 Celulose, Papel e Gráfica & 1.973 & 1.896 & 2.119 & 1.924 & 1.941 \\
\hline 10 Indústria da Borracha & 1.721 & 1.555 & 1.562 & 1.400 & 1.572 \\
\hline 11 Química & 1.543 & 1.599 & 1.647 & 1.501 & 1.746 \\
\hline 12 Farmacêutica e Veterinária & 1.738 & 1.736 & 1.729 & 1.580 & 1.662 \\
\hline 13 Indústria de Artigos de Plásticos & 1.857 & 1.862 & 1.672 & 1.549 & 1.768 \\
\hline 14 Indústria Têxtil & 1.943 & 1.968 & 1.885 & 1.680 & 1.739 \\
\hline 15 Vestuário, Calçados, Couros e Peles & 1.775 & 1.764 & 1.871 & 1.650 & 1.578 \\
\hline 16 Indústria do Café & 2.897 & 2.498 & 2.363 & 1.641 & 2.296 \\
\hline 17 Beneficiamento de Produtos Vegetais & 2.094 & 1.912 & 2.064 & 1.907 & 2.051 \\
\hline 18 Abate de Animais & 2.354 & 2.361 & 2.267 & 2.131 & 2.232 \\
\hline 19 Indústria de Laticínios & 2.320 & 2.137 & 2.012 & 1.916 & 2.065 \\
\hline 20 Fabricação de Açúcar & 1.847 & 2.049 & 1.956 & 1.928 & 2.123 \\
\hline 21 Fabricação de Óleos Vegetais & 2.352 & 2.356 & 2.387 & 2.258 & 2.211 \\
\hline 22 Fabricação de Outros Produtos Alimentares & 2.124 & 2.189 & 2.128 & 1.926 & 1.954 \\
\hline 23 Indústrias Diversas & 1.484 & 1.515 & 1.646 & 1.605 & 1.564 \\
\hline 24 Serviços Industriais de Utilidade Pública & 1.592 & 1.752 & 1.636 & 1.518 & 1.631 \\
\hline 25 Construção Civil & 1.671 & 1.603 & 1.610 & 1.397 & 1.442 \\
\hline 26 Comércio & 1.448 & 1.438 & 1.433 & 1.394 & 1.646 \\
\hline 27 Transporte & 1.446 & 1.575 & 1.517 & 1.443 & 1.622 \\
\hline 28 Comunicações & 1.322 & 1.248 & 1.245 & 1.182 & 1.284 \\
\hline 29 Instituições Financeiras & 1.271 & 1.198 & 1.153 & 1.300 & 1.311 \\
\hline 30 Aluguel de Imóveis & 1.235 & 1.212 & 1.150 & 1.070 & 1.054 \\
\hline 31 Administração Pública & 1.397 & 1.426 & 1.341 & 1.381 & 1.311 \\
\hline 32 Outros Serviços & 1.695 & 1.501 & 1.485 & 1.388 & 1.415 \\
\hline
\end{tabular}

Fonte: cálculos dos autores

* Para 1980, milhões de cruzeiros, para 1985, bilhões de cruzeiros, para 1990, milhões de cruzeiros e, para 1995 e 1999, mil reais.

É evidente a maior resposta da produção dos setores ligados à indústria alimentar (16 a 22) no decorrer dos anos em tela, embora a tendência decrescente seja observada para o conjunto, com exceção do setor Fabricação de Açúcar (20). Também a produção da Agropecuária (1) respondeu menos aos aumentos de demanda ao longo do tempo (Tabela 4). 
Com relação aos outros setores da indústria de transformação, cabe destacar Madeira e Mobiliário (8), Celulose, Papel e Gráfica (9), Indústria de Artigos Plásticos (13) e Indústria Têxtil (14) como os mais impactados pelo aumento nas demandas finais dos demais setores da economia paranaense, lembrando que os setores (9) e (14) foram setores-chave nos anos estudados, considerando os índices de ligações de Rasmussen-Hirschman.

Observou-se, também, para os setores Material Elétrico/Eletrônico (6), Material de Transporte (7) e Química (11) tendência de crescimento da produção em resposta a aumento das demandas finais dos anos 80 para os 90 . No caso dos dois primeiros, uma razão, detectada anteriormente, pode estar na diversificação do parque produtivo do Estado.

No que se refere aos setores do ramo serviços, os resultados mostram que eles foram os que menos responderam, em termos de produção, aos impactos advindos do aumento nas demandas finais setoriais. Entretanto, merece ser salientado o crescimento da produção dos setores Serviços Industriais de Utilidade Pública (24). Comércio (26) e Transporte (27), considerando os extremos do período (Tabela 4).

De uma forma geral, até 1990 os setores ligados à transformação (3 a 22) e os setores do segmento primário (1 e 2), responderam, de forma crescente, aos aumentos das demandas finais, enquanto de 1990 para 1999 observa-se uma redução nesse comportamento. Considerando que houve uma redução dos índices de ligações, tanto Rasmussen-Hirschman quanto puros, ao longo dos anos observados, revelando assim menores ligações intersetoriais no interior da economia paranaense, a possibilidade de os aumentos nas demandas finais setoriais serem atendidos por setores externos à economia estadual, seja de outros Estados, seja do exterior, é grande.

\section{CONSIDERAÇÕES FINAIS}

A análise da estrutura produtiva da economia paranaense mostrou que, ao longo dos anos 80 e 90, as relações intersetoriais estão se alterando na direção dos setores da indústria de transformação e dos serviços, mostrando que o Estado está diversificando seu parque produtivo e se tornando menos dependente da agropecuária e dos setores alimentares enquanto propagadores de seu crescimento e desenvolvimento.

Por outro lado, os índices de ligações, tanto os de Rasmussen-Hirschman quanto os puros, reduziram suas magnitudes ao longo do período analisado, o que mostra menores ligações intersetoriais dentro da economia estadual, revelando que estas estão se intensificando com os setores de outros Estados ou com do exterior.

Quanto aos impactos das demandas finais setoriais na produção, cabe destacar a importância dos setores da indústria alimentar como os que mais contribuíram ao longo do período. No entanto, a análise dos multiplicadores de produção parece confirmar a maior integração dos setores à economia paranaense com o exterior, como mencionado acima, na medida em que os efeitos dos aumentos nas demandas finais setoriais sobre a produção se mostraram decrescentes com o processo de abertura comercial dos anos 90.

Por fim, fica evidente, a partir dos resultados obtidos, que há necessidade de um acompanhamento da evolução da economia paranaense para períodos posteriores ao aqui analisado. A partir da elaboração de matrizes para períodos mais recentes, será possível, inclusive, melhorar as análises a respeito da influência de diversos fenômenos como, por exemplo, a instalação das montadoras e as oscilações no agronegócio e seus impactos nos diversos segmentos da economia paranaense. Desse 
modo, com base mais sólida e atual, estaria disponível um importante instrumento não só para a pesquisa, mas também para as políticas públicas e privadas estaduais.

\section{REFERÊNCIAS BIBLIOGRÁFICAS}

Cella, G. The input-output measurement of interindustry linkages. Oxford Bulletin of Economics and Statistics, v. 70, p. 705-712. 1984.

Clements, B. On the decomposition and normalization of interindustry linkages. Economics Letters, v. 33, p. 337-340, 1990.

Clements, B. J.; Rossi, J. W. Interindustry linkages and economic development: the case of Brazil reconsidered. The Developing Economies, v. 29, p. 166-187, 1991.

Ligações interindustriais e setores-chave na economia brasileira. Pesquisa e Planejamento Econômico, v. 22, p. 101-124. 1992.

Guilhoto, J. J. M; Sonis, M.; Hewings, G. J. D; Martins, E. B. Índices de ligações e setores-chave na economia brasileira: 1959/80. Pesquisa e Planejamento Econômico, v. 24, n. 2, p. 287-314, 1994.

Guilhoto, J. J. M.; Sonis, M.; Hewings, G. J. D. Linkages and multipliers in a multiregional framework: integration of alternative approaches. Urbana: University of Illinois. Regional Economics Applications Laboratory, 1996. 20p. (Discussion Paper, 96-T-8).

Guilhoto, J. J. M.; Sesso Filho, U. A. Estimação da matriz de insumo-produto a partir de dados preliminares das contas nacionais. Economia Aplicada, v. 9, n. 2, p. 277-299, abr./jun. 2005.

Hewings, G. J. D. The empirical identification of key sectors in an economy: a regional perspective. The Developing Economies, v. 20, p. 173-195, 1982.

Hirschman, A. O. The strategy of economic development. New Haven: Yale University Press, 1958. 217p.

Lourenço, G. M. Evolução recente e perspectivas das economias regionais segundo a F.G.V. Análise Conjuntural, v. 16, n. 1-2, p. 3-6, jan.-fev. 1994.

McGilvray, J. W. Linkages, key sector and development strategy. In: Leontief, W. (ed.) Structure, system and economic policy. Cambridge: Cambridge University Press, cap. 4, p. 49-56. 1977.

Moretto, A. C. Relaçôes intersetoriais e inter-regionais na economia paranaense em 1995. Piracicaba: 2000. 161p. Tese (Doutorado) - Escola Superior de Agronomia Luiz de Queiroz, Universidade de São Paulo.

Miller, R. E.; Blair, P. D. Input-output analysis: foundations and extensions. Englewood Cliffs, New Jersey: Prentice-Hall, Inc., 1985. 464p.

Miazawa K. Input-output analysis and the strusture of income distribution. (Mathematical economics-Lectures notes in economics and mathematical systems, 116). Germany: Springer-Verlag, 1976. 135p.

Myrdal, G Solidaridad o desintegración. México, DF, Buenos Aires, Fondo de Cultura Económica, 1957.

Parré, J. L.; Alves, A. F. Matriz de insumo-produto para o Paraná, 1996 e 1999. (Documento Interno). Universidade Estadual de Maringá, Paraná, 2002.

Perroux, F. Conceito de pólos de crescimento. In: Schwartzman, J. (ed.) Economia regional: textos escolhidos. Belo Horizonte: CEDEPLAR, p. 145-156, 1977.

Rasmussen, P. N. Studies in intersectoral relations, Amsterdam: North-Holland, 1956.

Rodrigues, R. L. Cooperativas agropecuárias e relações intersetoriais na economia paranaense: uma análise de insumo-produto. Piracicaba: 2000. 171p. Tese (Doutorado) - Escola Superior de Agronomia Luiz de Queiroz, Universidade de São Paulo.

Rodrigues, R. L. Guilhoto, J. J. M.; Moretto, A. C. Cooperativas agropecuárias e estrutura produtiva paranaense: relações setoriais, emprego e renda nos anos 90. Anais do V Encontro de Economia Região Sul. Florianópolis, 26 e 27 de setembro de 2002. 
Rodrigues, R. L. Guilhoto, J. J. M. Estrutura produtiva, relações intersetoriais e cooperativas agropecuárias no Paraná em 1980 e 1985. Revista de Economia e Sociologia Rural, v. 42, n. 2, p. 243-266, abr-jun.

Schaffer, W. A. Regional impact models. In: The web book of regional science. Morgantown, WV: Ed. S. Loveridge, West Virginia University, Regional Research Institute, 1999. 88p.

Sonis, M.; Hewings, G. J. D. Error and sensitivity input-output analysis: a new approach. In: Miller, R. E.; Polenske, K. R.; Rose, A.Z. (ed.) Frontiers of input-output analysis. New York: Oxford University Press, 1989.

Sonis, M.; Hewings, G. J. D. Fields of influence in input-output systems. Urbana: University of Illinois. Regional Economics Applications Laboratory, 1994. Mimeo.

Trintin, J.G. A economia paranaense: 1985-1998. Campinas, 2001. 200 p. Tese (Doutorado) - Instituto de Economia, Universidade de Campinas.

Vasconcelos, J. R. de; Castro, D. Paraná: economia, finanças públicas e investimentos nos anos 90. Brasília: IPEA, 1999. (Texto para Discussão, 624). 